\title{
Interactive comment on "Sandbagging versus Sandbag Replacement Systems: Costs, Time, Helpers, Logistics” by L. Lankenau and B. Koppe
}

\section{Lankenau and B. Koppe \\ lena.lankenau@hs-bremen.de}

Received and published: 21 August 2019

Dear Referee \#2, Thank you very much for your review. At the suggestion of two further reviews on this article (nhess-2019-165) and on the article nhess-2019-164 it is planned to summarize the two articles. This will also include more literary references not only from Germany, but also beyond. We will include a proper explanation to Figure 1. Considering the addressed German terms in Table 1 - these terms are product names. Nevertheless, we will try to translate them into English, where possible and appropriate. Considering the mentioned application field of SBRS: Sandbags as well as SBRS are used in emergency flood control - especially in case permanent flood protection systems like dikes are failing or in case no permanent flood protections schemes are available because the currently endangered area was thought not

Printer-friendly version

Discussion paper 
to be at risk. Thus, sandbags as well as SBRS are certainly used in extreme flood events. Concerning the hydraulic efficiency of sandbags and SBRS, we would like to add a summary paragraph on water heads and seepage rates realized in testing but would also like to refer to the paper Massolle et al. 2018 for more information. In Massolle et al. 2018, the hydraulic testing of different sandbag and SBRS systems also relevant for the present papers nhess-2019-164 and nhess-2019-165 are described in detail. By merging the two papers nhess-2019-164 and nhess-2019-165 discussion on 'mechanical influences' and 'vandalism' will be added. In chapter 3 the terms 'helpers', 'THW-helpers', 'employees' will be checked for consistency. Furthermore, a clear explanation will be given on cost calculation for helpers (e.g. costs for trained or not-trained helpers). In chapter 3.1, the cost estimation of 5 Euro per helper and day is only related to the costs for upper control like disaster control management, technical incident command and platoon, but not for the helper itself. These are realistic overhead costs related to the number of helpers in action. Considering justification of values like 'costs of materials' and 'costs of trucks' etc. we will add more information and will review all positions for traceability. In Table 3 the term ' 2.5 helpers including lower command' means that 2 helpers are busy in installation and dismantling of the SBRS. Another one helper on the lower command level can take care for two different areas of application - therefore only half a helper is counted. In total 2.5 helpers. Concerning the conclusion: we will clean the conclusion from political statements. Concerning the English language - we will have another review of the grammar and in particular will check the technical terms for accuracy and consistency.

Interactive comment on Nat. Hazards Earth Syst. Sci. Discuss., https://doi.org/10.5194/nhess2019-165, 2019.

Printer-friendly version

Discussion paper
Interactive

comment 